\title{
Vegetative aquaculture of Fucus in the Baltic Sea-obtaining low-fertility biomass from attached or unattached populations?
}

\author{
Rafael Meichssner ${ }^{1,2}$ (i) $\cdot$ Peter Krost $^{2} \cdot$ Rüdiger Schulz $^{1}$ \\ Received: 20 August 2020 /Revised and accepted: 3 January 2021 / Published online: 15 March 2021 \\ (C) The Author(s) 2021
}

\begin{abstract}
An experimental farm has been installed in the Kiel Fjord, western Baltic Sea, aiming at the development of a sustainable production process for Fucus species (Fucus vesiculosus, Fucus serratus). The envisaged cultivation method includes the unattached rearing of thalli in baskets deployed in the sea and their vegetative reproduction. Fertility (i.e., receptacle formation) is expected to be problematic for this approach, because receptacles are terminated in growth and degrade after gamete release. In culture experiments, natural fertility led to only minimal overall growth in $F$. vesiculosus and even weight loss in $F$. serratus. Therefore, we tested if long-term unattached cultivation of formerly attached thalli leads to a lowering of fertility by an acclimatization process. However, fertility after 1 and 2 years of unattached cultivation was statistically equal and still comparable to the high fertility of attached populations. Furthermore, we tested if the only known naturally unattached population in the western Baltic Sea near Glücksburg, which remains largely infertile in the wild, keeps its low fertility if put under culture conditions. During an experimental 1-year cultivation, thalli from this population remained almost entirely vegetative $(2.0 \pm 3.1 \%$ fertile apices). Hence, the Glücksburg population is a promising source of aquacultural seedling biomass. Yet, further tests are necessary to check, if the fertility remains low over several years of cultivation. If unattached populations are used as source for commercial cultures, the collection of seedling material should always be accompanied by strong measures to ensure the continued integrity of these valuable habitats.
\end{abstract}

Keywords Fucus vesiculosus $\cdot$ Fucus serratus $\cdot$ Phaeophyceae $\cdot$ Aquaculture $\cdot$ Ecad $\cdot$ Vegetative reproduction $\cdot$ Fertility

\section{Introduction}

The brown algal genus Fucus is known for its high content in bioactive ingredients like phlorotannins and fucoxanthin (Catarino et al. 2018). Fucus biomass is therefore used for a variety of products like cosmetic extracts and food supplements (Ferreira et al. 2019; Torres et al. 2020). Currently, the entire market demand is satisfied by biomass harvested from wild populations, e.g., in France and Ireland (netalgae. eu). In Germany, harvesting from wild populations is prohibited and Fucus stands listed as protected habitat (Bundesamt für Naturschutz 2013; HELCOM 2013). Yet, German companies desire regional biomass, because

Rafael Meichssner

rafael.meichssner@crm-online.de; rmeichssner@bot.uni-kiel.de

1 Physiology and Biotechnology of the Plant Cells, Christian-Albrechts-University, Kiel, Germany

2 CRM (Coastal Research \& Management), Kiel, Germany "regionality" is a valuable claim in the targeted markets (L. Piker, pers. comm.). The only means to obtain regional biomass from the German Baltic Sea coast is therefore aquaculture. Fucus aquaculture could potentially become necessary in other countries, too, if the market pull increases (Cherry et al. 2019), or environmental change puts wild populations at risk (Nicastro et al. 2013). Consequently, an experimental Fucus farm has been established in the Kiel fjord at the German Baltic Sea coast aiming at the development of a method for the production of local Fucus species (Fucus vesiculosus, Fucus serratus) in aquaculture.

A key step in the development of a commercial cultivation process is the establishment of a successful reproduction method. Commercially cultivated seaweeds can be placed in two categories with respect to reproduction: The first is produced in a process involving sexual reproduction (e.g., Saccharina latissima, Undaria pinnatifida, Pyropia spp.), including the rearing of different life stages (gametophyte, (tetra-)sporophyte, in red algae also carposporophyte), the production of seeded ropes in land-based hatcheries, and their later deployment in the sea for the outgrowth of the germlings 
to harvest size (Yarish and Pereira 2008; Graham et al. 2009; Hurd et al. 2014; Azevedo et al. 2019). The second category is produced in a process involving vegetative reproduction (Eucheuma spp./Kappaphycus spp., Gracilaria spp.), where thalli are reared either tethered to ropes, pegged to the sediment, or freely floating in tanks or baskets. Fragments for the next growing season ("seedlings") are obtained by cutting small pieces from the cultivated thalli. No hatchery is needed for vegetative reproduction and only one stage of the life cycle is cultivated (Yarish and Pereira 2008; Graham et al. 2009; Hurd et al. 2014). Due to the ease of the process, vegetative reproduction was envisaged for Fucus aquaculture. The overall cultivation method comprises the cutting of fronds from wild specimens, which grow unattached in floating baskets until harvest size (Fig. 1). From the harvest, small pieces containing apical meristems are generated, e.g., by automated shredding, which are used as seedlings for the next growing season, and so forth.

Typical wild Fucus populations produce high numbers of sexual structures (receptacles) at their thallus apices. During receptacle formation, the activity of the apical meristem is terminated and, after shedding of the gametes, the receptacle including the former meristem and the tissue below the receptacle degrades down to the next branch that bears a vegetative apex (Knight and Parke 1950; Moss 1967). During a typical reproductive season, $70-100 \%$ of the apices turn into receptacles and degrade later (Knight and Parke 1950; Bäck et al. 1991; Graiff et al. 2017), which causes attached Fucus populations to lose significant amounts of biomass $(F$. vesiculosus: ca. 25\% (Berger et al. 2001), F. serratus: 30-50\% (Arrontes 1993; Brenchley 1996)). This process is expected to lead to severe growth reductions in unattached cultures which consist only of fronds. However, these fertility-related growth reductions have not been precisely determined yet, and it is unclear how detrimental they are for successful cultivation. In general, culture biomass with constantly low fertility is expected to be advantageous for effective biomass production with the described cultivation method.

Interestingly, there are some Fucus populations occurring in certain habitats like estuaries, salt marshes, or blue mussel banks, which naturally produce no or only few receptacles and would thus be very suitable for vegetative cultivation (Norton and Mathieson 1983; Mathieson and Dawes 2001). These populations are not found attached to hard substrata but live entangled in salt marsh angiosperms, embedded in mud, or are held by the byssus filaments of blue mussels (Baker and Bohling 1916; Nienburg 1925; Nienhuis 1970; Norton and Mathieson 1983). It is usually assumed that they initially
Fig. 1 a Package of cultivation baskets for experiment 1 (bottom, quadratic) and cultivation baskets for experiment 3 (top, round). b White boxes with side windows installed in the Jetfloat system. c Packages of cultivation baskets for experiment 2 which were inserted in the white boxes shown in $\mathbf{b}$

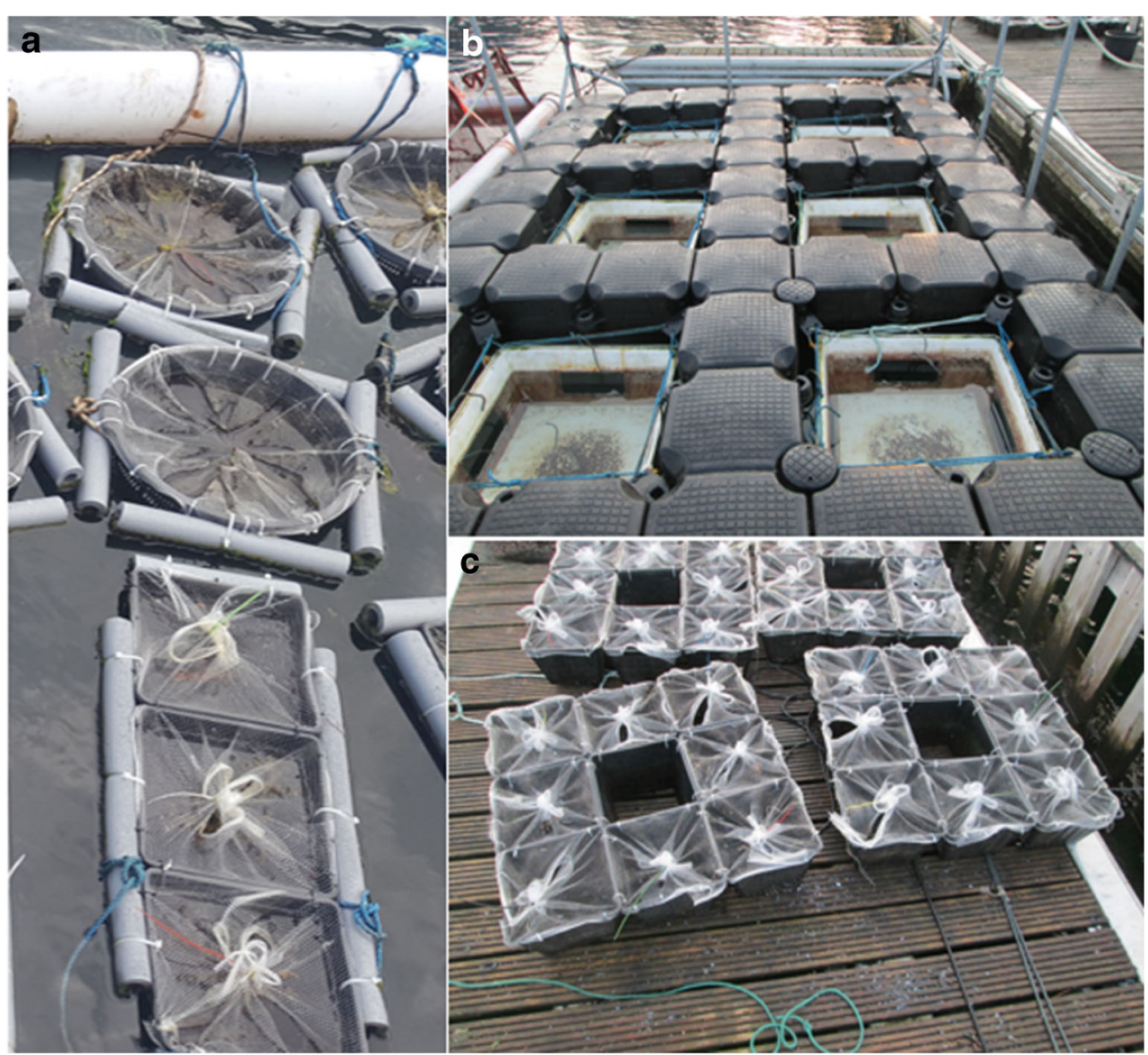


had a holdfast, but were pulled off from their substrate and drifted to their current location, where angiosperms, mud, or blue mussel byssus filaments prevented them from being washed ashore (Norton and Mathieson 1983). Being trapped this way, they are supposed to have reproduced by vegetative fragmentation, thus forming larger populations (Mathieson et al. 2006). They share some typical features like absence of holdfast, low fertility, i.e., almost no receptacles, often small size, and atypical, curling growth. Due to these features, they are termed "ecads" to indicate that their morphology is a result of the environmental conditions (e.g., Baker and Bohling 1916). However, there is some confusion if the unusual morphological features, especially the low fertility, arose from acclimatization to the specific conditions of their current growth locations, or if it required adaptation, i.e., only certain genotypes, which show low fertility or are able to quickly shift towards low fertility, have successfully colonized these locations after arrival (Wallace et al. 2004; Mathieson et al. 2006).

Some unattached populations have been shown to be hybrids of $F$. vesiculosus and $F$. spiralis (Wallace et al. 2004; Coyer et al. 2006; Mathieson et al. 2006; Sjøtun et al. 2017), or result from backcrosses between these hybrids and F. vesiculosus (i.e., introgression, Wallace et al. 2004), or they are polyploids of $F$. vesiculosus (Coyer et al. 2006; Sjøtun et al. 2017). As hybridization and polyploidy are known to often cause sterility in land plants, it can be speculated that these genetic changes are causal for the low fertilities of these populations, which in turn can be regarded as a result of adaptation and not acclimatization. However, in the study of Mathieson et al. (2006), thalli of the unattached $F$. spiralis ecad lutarius, found in the Gulf of Maine, were genetically equal to neighboring attached $F$. vesiculosus or $F$. spiralis, which indicates an acclimatization origin of these thalli, but it was questioned how long they might persist as "ecads."

From the western Baltic Sea, only one unattached population is known from Glücksburg in the Flensburg fjord (Maczassek 2014), where thalli morphologically similar to $F$. vesiculosus are found embedded in mud, showing a strikingly low number of receptacles. So far, the genetic affinities of this population are unresolved. Maczassek (2014) first described it as $F$. vesiculosus f. mytili, although the genetic relationship between the unattached population from Glücksburg and $F$. vesiculosus f. mytili, an unattached population described from the Wadden Sea (Nienburg 1931), is unclear. Therefore, we use the term "Glücksburg population" in the following. Maczassek (2014) hypothesized that it arose through acclimatization of local attached $F$. vesiculosus thalli and that the acclimatization process was induced by detachment from the substrate. Following this reasoning, the longterm cultivation of local attached $F$. vesiculosus thalli with the envisaged cultivation protocol, which includes the detachment of thalli from the substrate and their unattached rearing, could potentially induce an acclimatization towards the morphology of the Glücksburg population, including the low fertility.

If the Glücksburg population itself is put under culture conditions, it will retain its low fertility if this feature is genetically fixed. If the low fertility is the result of an acclimatization process, it could also be retained depending on the culture conditions. In any of the two scenarios, the Glücksburg population itself could potentially be a useful seedling source for aquaculture. For successful vegetative cultivation, it is crucial to know, if biomass which continuously remains at a state of low fertility, can be obtained via acclimatization from attached populations and/or if the unattached Glücksburg population can be used, because it retains its low fertility in culture. From a quantitative perspective, the acclimatization of former attached thalli would be advantageous, because most of the $402 \mathrm{~km}$ of the western Baltic Sea coastline of Germany (Schleswig-Holstein) are colonized by attached $F$. vesiculosus and $F$. serratus populations (Fürhäupter et al. 2008), while the Glücksburg population only covers an area of about $50 \mathrm{~m}^{2}$ in the Flensburg fjord and thus represents only a limited source for seedling material.

Based on these considerations, three questions were addressed in this study:

(1) How strong is the fertility-related reduction of growth in unattached culture, and is it detrimental for commercial cultivation (Experiment 1)?

(2) Do Fucus thalli from attached populations (F. vesiculosus, $F$. serratus) survive long-term unattached cultivation, and does this long-term unattached cultivation reduce the fertility? Specifically, are less receptacles formed in the second year of unattached culture than in the first year of unattached culture (Experiment 2)? F. serratus was included in this experiment, although the acclimatization hypothesis of Maczassek (2014, see above) only concerned F. vesiculosus.

(3) Do thalli from the Glücksburg population grow in culture and does their fertility change under culture conditions (Experiment 3)?

\section{Materials and methods}

All experiments were conducted at the premises of Kieler Meeresfarm ( $\mathrm{GmbH} \& \mathrm{Co} . \mathrm{KG})$, located in the northwestern part of the Kiel fjord ( 54.381975 N; 10.162034 E). For experiments 1 and 2, individuals from local attached populations were collected, Fucus vesiculosus from Kiel/Holtenau (54.368966 N; 10.154112 E) and Fucus serratus from Bülk (54.455146 N; 10.198858 E). For experiment 3, individuals from the Glücksburg population were collected from its only known growth location in the Flensburg fjord (54.837671 N; 
9.521850 E, Fig. 2). For all experiments, whole plants were transported in seawater to the cultivation site and stored in buckets overnight. The following day, thallus pieces of 3$10 \mathrm{~cm}$ in length ( $F$. vesiculosus and Glücksburg population) and $5-15 \mathrm{~cm}$ in length ( $F$. serratus) were cut from the plants and used to start the experimental cultures. The sizes represent typical fronds of the species, when cut above the stipe. The size difference was accepted, because no inter-species comparisons were intended. Measured response variables during the experiments were wet weight, total number of apices, and fertility. Wet weight was regularly assessed by weighing the cultured biomass with a lab scale (Kern EMB 1200) under wind protection after $15 \mathrm{~s}$ of drying with a salad spinner. The total number of apices was assessed by counting all apices in the experimental cultures. Apices were counted as "1," if the gap between two dividing apices was smaller than $1 \mathrm{~mm}$, and as " 2 ," if it was larger than $1 \mathrm{~mm}$. Fertility was calculated as the percentage of fertile apices (receptacles) of the total number of apices. An apex was considered as fertile as soon as receptacle formation was initiated, discernable by a commencing swelling of the apex and the formation of high numbers of conceptacles (visible when thalli were hold up against the light).

\section{Experiment 1-effect of fertility on growth in culture}

In order to test the impact of fertility on the growth of cultivated Fucus thalli, culture biomasses with different initial fertilities were created by assembling thalli with ripe fertile and vegetative apices. The following groups were prepared: F. vesiculosus: $100 \%$ receptacles, $80 \%$ receptacles, $0 \%$ receptacles; $F$. serratus: $100 \%$ receptacles, $70 \%$ receptacles, $0 \%$ receptacles.

For $F$. vesiculosus, $80 \%$ receptacles represents the estimated fertility during the spring reproductive season (Graiff et al. 2017, own pre-experiments). The experiment for this species was started during this season (14 May 2019) and lasted until 04 September 2019. Measurements of response variables were performed ca. weekly due to the high growth rates during summer. For $F$. serratus, $70 \%$ receptacles represents the estimated fertility during its reproductive period in late autumn/ winter (own pre-experiments). The experiment for this species was therefore started on 20 December 2019 and lasted until 1 April 2020 with measurements every 2-4 weeks due to the low growth rates during winter. The difference in season was accepted, because a direct comparison of the two species was not intended.

The same experimental setup was used for both species: nine black plastic baskets (BAUHAUS; Oase Pflanzkorb; edge length: $28 \mathrm{~cm}$; volume: $14 \mathrm{~L}$ ) served as cultivation devices, allowing for permanent inflow of seawater by holes of ca. $0.3 \times 0.3 \mathrm{~cm}$ at all sides. The baskets were arranged in three packages of three and covered with transparent plastic nettings to avoid loss of culture material (Fig. 1). Each of the three groups $(100 \%$; $80 \% / 70 \%$; $0 \%)$ was represented with one replicate in each of the three packages, at a different position in each package. Thus, position effects could be excluded. The packages were deployed in the sea with polyethylene foam pipe insulation as floating bodies (Fig. 1). The packages were protected from wave activity by a pipe frame $(2 \times 4 \mathrm{~m})$. Cultures were started with $20 \mathrm{~g}$ biomass of the respective fertility per basket. The total number of apices at the beginning of the experiments was not equal among the groups, because receptacles are heavier than vegetative thallus apices. Therefore, the percentual change of the total number of apices was calculated as an additional response variable using the following formula:

Percentual change of total number of apices

$$
=\left(\left(\mathrm{TNA} t_{\text {end }} / \mathrm{TNA} t_{0}\right) / \mathrm{TNA} t_{0}\right)=\times 100
$$

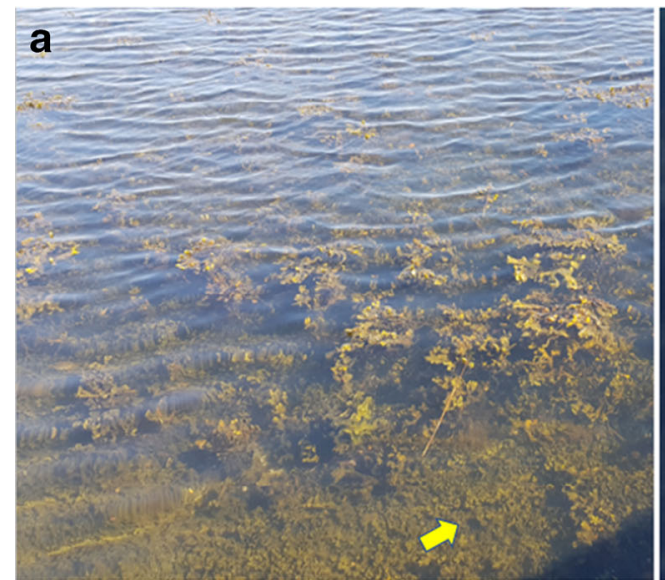

Fig. 2 a Glücksburg population growing embedded in mud (see arrow) in the understory of larger $F$. vesiculosus thalli with receptacles. b Thalli

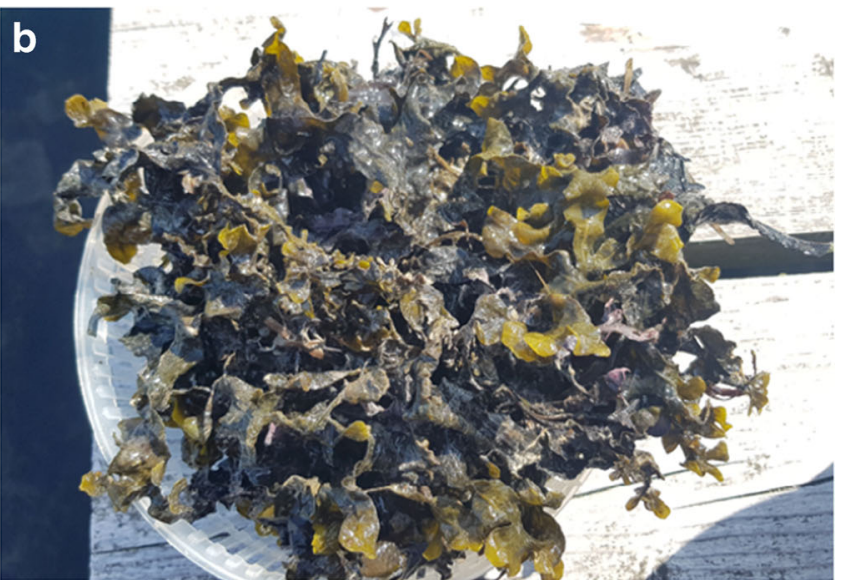

from Glücksburg population after collection, showing no receptacles and a dark coloration of the thallus parts that were embedded in anoxic mud 
where TNA is the total number of apices, $t_{0}$ is the beginning of the experiment, and $t_{\text {end }}$ is the end of the experiment.

The weight data were of main interest and are presented here; the total number of apices, the fertility over the course of the experiment, and the percentual change of the total number of apices are shown in the supplementary material (Fig. 3, Fig. $\mathrm{S} 1, \mathrm{Tab} . \mathrm{S} 1)$.

\section{Experiment 2-fertility of attached populations un- der long-term unattached culture}

In order to investigate the growth and fertility of formerly attached thalli during long-term unattached culture, $F$. vesiculosus and $F$. serratus thalli were cultivated unattached for 24 months (24 May 2018-29 May 2020) in the same type of plastic baskets used in experiment 1 . The baskets were not submerged directly into the sea as in experiment 1, but inserted into white boxes (glass fiber reinforced plastic, shape: turned truncated pyramid, upper opening: $80 \times 80 \mathrm{~cm}$, basal area: $64 \times 64 \mathrm{~cm}$, height: ca. $40 \mathrm{~cm}$, Fig. 1). The white boxes had a window $(35 \times 37 \mathrm{~cm})$ at each of the four side faces to allow water inflow. They were hung in the gaps of a swimming platform of black Jetfloat elements (Jetfloat International, double elements: $100 \times 50 \times 40 \mathrm{~cm}$, single elements: $50 \times$ $50 \times 40 \mathrm{~cm}$, Fig. 1). Thus, the baskets were deployed in the sea, but with less water flow-through than under direct deployment, resulting in significantly less epizoans colonizing the thalli (e.g., barnacles, blue mussels, bryozoans), than if baskets were directly deployed in the sea (own pre-experiments). Using this setup it was possible to conduct a long-term cultivation experiment without the necessity of frequent cleaning of the thalli from epibionts, which might have caused considerable damage to the thalli (own pre-experiments). Six white boxes were available, containing a package of eight black baskets each, resulting in a total of 48 experimental units. The white boxes were only used for installation and hence not considered as entities; thus, the 48 baskets were considered as independent experimental units. The position of the baskets within the white boxes was changed regularly to avoid position effects. Of the 48 baskets, 36 were used for other experiments and 12 were used for this experiment, yielding 4 groups of 3 replicates each:

- F. vesiculosus: unattached cultivation starting on 24 May 2018

- F. vesiculosus: unattached cultivation starting on 24 May 2019

- F. serratus: unattached cultivation starting on 24 May 2018

- F. serratus: unattached cultivation starting on 24 May 2019
The experimental cultivation was started with $20 \mathrm{~g}$ of vegetative thalli per basket and lasted until 29 May 2020. Thus, for each Fucus species, one group was cultivated unattached for 2 years and the second group was cultivated unattached for 1 year, parallel to the second year of the first group (Figs. 4 and 5). Weight was recorded during the entire experiment. The total number of apices (data not shown) and fertility was recorded three times during the first year and every 2-4 weeks during the second year. Thus, it was possible to compare the fertility of the group cultivated for 2 years between year 1 and year 2 . Furthermore, it was possible to compare the fertility of the group cultivated for 2 years with the fertility of the group cultivated for 1 year at the same time points and under the same environmental conditions during year 2. A higher measurement frequency was chosen during year 2 to ensure the detection of even small fertility differences between the two groups cultivated in parallel.

During year 1, a harvest was performed in September 2018 to avoid limitation of growth by too high densities. Density limitation occurs above ca. $100 \mathrm{~g}$ basket $^{-1}$ (i.e., ca $2.5 \mathrm{~kg} \mathrm{~m}^{-2}$ ) (own pre-experiments). During this harvest, all sexual thalli were removed and the cultures were continued with $20 \mathrm{~g}$ of vegetative thalli. After 1 year of cultivation (24 May 2019), the biomass was again harvested and cultivation was continued with the vegetative biomass present in the cultures at this point ( $F$. vesiculosus: $6 \mathrm{~g} ; F$. serratus: $11 \mathrm{~g}$ ), with the parallel groups of year 2 being added to the experiment (F. vesiculosus: $6 \mathrm{~g} ;$ F. serratus: $11 \mathrm{~g}$ ).

Fucus vesiculosus shows two reproductive periods in the western Baltic Sea, the first from November to May (spring reproductive season (SRS)) and the second from July to November (autumn reproductive season (ARS)). Two genotypes occur in the Kiel Bay, from where the thalli were collected; the first genotype is fertile only during the SRS ("only spring bloomers") and the second genotype shares this reproductive period but is fertile also during the ARS ("autumn and spring bloomers") (Berger et al. 2001, F. Weinberger, pers. comm.). Vegetative thalli of these two genotypes cannot be distinguished in the field. Therefore, thalli were randomly picked and initially both genotypes were present in the culture biomass in the ratio of the natural field populations. The ratio of the two genotypes changed unintentionally during year 1 , due to the intermediate harvests (see "Results").

Fucus serratus has only one long reproductive period from July to March (winter reproductive season (WRS)) in the western Baltic Sea and no genotypic variants with respect to reproductive behavior have been observed in the sampling area (pers. observation, see also Malm et al. (2001) for similar observations at the Swedish Baltic Sea coast). 


\section{Experiment 3-fertility of unattached Glücksburg population in culture}

In order to investigate if biomass from the unattached Glücksburg population retains its low fertility under culture conditions, thalli were cultivated for 1 year. Four larger black plastic baskets (BAUHAUS; Oase Pflanzkorb; round; diameter: $40 \mathrm{~cm}$; volume: $35 \mathrm{~L}$ ) were used as cultivation devices and tethered individually to the $2 \times 4$-m pipe frame using the same floating bodies as in experiment 1 (Fig. 1). The experiment was started on 29 June 2019 with 55-62 g of thalli, which was cultivated until 29 June 2020. Weight, total number of apices, and fertility were recorded regularly. No intermediate harvests were necessary, because the limiting density was not reached in this experiment. Epibionts had to be carefully removed in November 2019, since the thalli were heavily colonized. This was not necessary in experiments 1 and 2.

\section{Statistics}

Statistical analysis was performed using the R software package (R Core Team 2013). For experiment 1, weight and fertility of experimental groups at $t_{\text {end }}$ as well as percentual change of the total number of apices over the experimental time were compared by one-way ANOVA and Tukey's HSD post hoc test. For experiment 2, the fertility of the experimental groups was compared by Welch's two-sample $t$ test at defined time points of the experimental cultivation period. Experiment 3 did not require statistical analysis. Normality of residuals was tested by Shapiro-Wilk's test and homogeneity of variances was tested by Fligner's test. $p$ values below 0.05 were considered statistically significant. The detailed results of the statistical analysis are depicted in the supplementary material (Tab. S2-S5).

\section{Results}

\section{Effect of fertility on growth in culture (experiment 1)}

Both species showed strong growth when the initial culture biomass consisted only of vegetative thalli, but showed only marginal growth or even weight loss, when the biomass consisted of thalli with the typical fertility found in attached wild populations ( $F$. vesiculosus: $80 \%$, F. serratus: $70 \%$ ), or when the biomass consisted of thalli with $100 \%$ fertility (Fig. 3). Detailed results are given in the following:

For $F$. vesiculosus, thalli of the purely vegetative treatment ( $0 \%$ fertility) increased in weight from $20 \mathrm{~g}$ to $126 \pm 16 \mathrm{~g}$ during the experimental time, while thalli in the other two treatments, after an initial weight increase ending at mid of July, showed only slight growth or even weight decreases
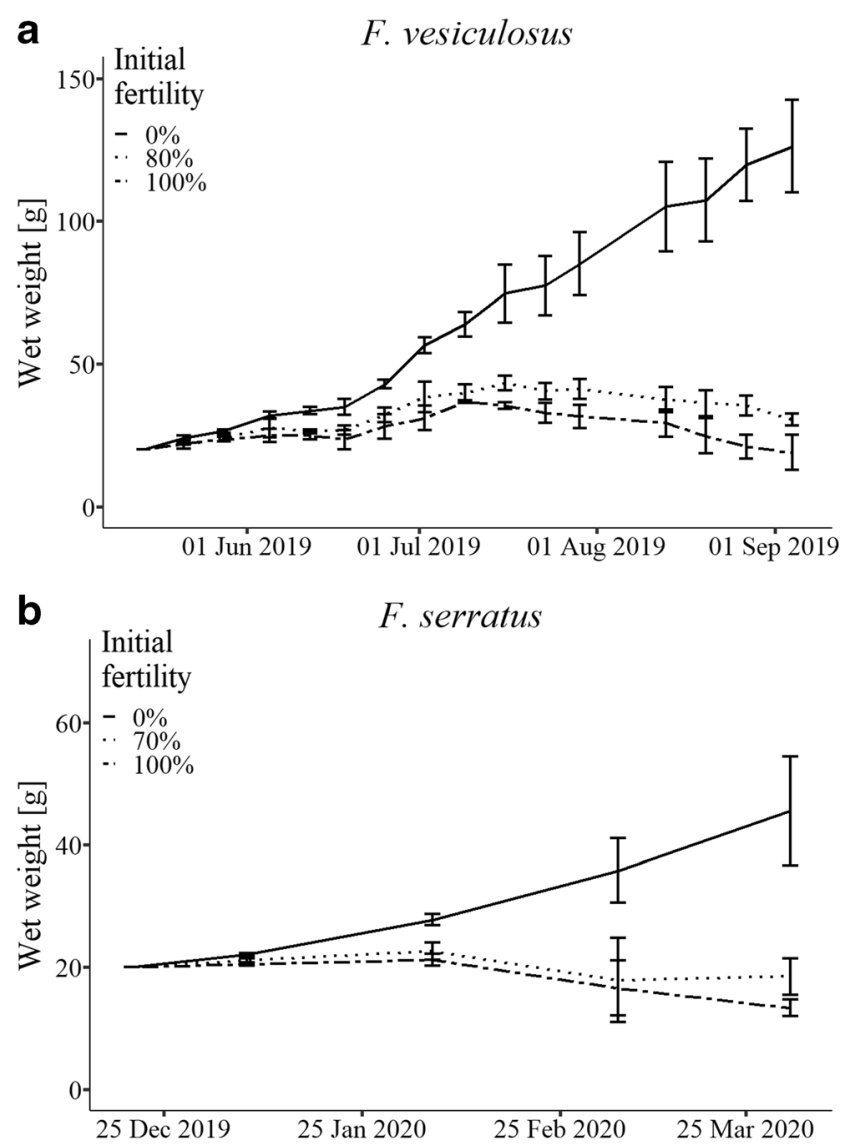

Fig. 3 Effect of fertility status at the beginning of experimental cultivation (termed "initial fertility," measured as percentage of receptacles of total number of apices) on wet weight of $F$. vesiculosus (a) and F. serratus (b). Data displayed as mean $\pm \mathrm{SD}, N=3$ baskets. The total number of thallus apices and the fertility during the subsequent cultivation period are shown in the supplementary material (Fig. S1)

ending at $30 \pm 2 \mathrm{~g}$ for the $80 \%$ treatment and at $19 \pm 6 \mathrm{~g}$ for the $100 \%$ treatment (one-way ANOVA of weight at $t_{\text {end }}: p=$ $2.3 \times 10^{-5}$, significant differences in post hoc Tukey's HSD between 100 and $0 \% ; 80$ and $0 \%$, Fig. 3).

For $F$. serratus, the thalli of the $0 \%$ treatment showed a weight increase from 20 to $42 \pm 9 \mathrm{~g}$ during the time frame of the experiment (Fig. 3). At the same time, the thalli of the $70 \%$ treatment decreased in weight from 20 to $18 \pm 3 \mathrm{~g}$ and the thalli of the $100 \%$ treatment from 20 to $13 \pm 1 \mathrm{~g}$ by slow degradation of the receptacles and the thallus tissue below the receptacles (one-way ANOVA of weight at $t_{\text {end }}: p=$ 0.0021 , significant differences in post hoc Tukey's HSD between 100 and $0 \% ; 80$ and $0 \%$ ). The weight results of both species were paralleled by the total number of apices (Supplementary material, Fig S1). The fertility during the experiment matched the expectations with an increasing share of vegetative thalli over time in the groups that contained vegetative apices and no change in the $100 \%$ group (Supplementary material, Fig. S1). 


\section{Fertility of attached populations under long-term unattached culture (experiment 2)}

It was possible to cultivate both Fucus species for 2 years as unattached thalli. They remained viable and produced new biomass from the vegetative apices present in the cultures (Figs. 4 and 5). The fertility of both species was not reduced during the 2 years of cultivation. It was statistically equal between year 1 and year 2 of the same culture and between cultures of different ages (first vs. second year in culture) during the same year (Figs. 4 and 5). As it remained at the high levels typical for wild attached populations, no acclimatization towards low fertility, which is typical for wild unattached populations, could be observed. However, for both species, unattached cultivation over time led to disoriented, twisted growth (Fig. 6), resulting in a morphology similar to that of unattached populations in the wild (Norton and Mathieson 1983). In addition, $F$. vesiculosus thalli showed a reduction in width, which has also been observed in wild unattached populations (Mathieson and Dawes 2001; Mathieson et al. 2006). Species-specific results will be given in the following:

Fucus vesiculosus showed fast growth during the first months of cultivation reaching $57 \pm 5 \mathrm{~g}$ after 2.5 months; therefore, a harvest to $20 \mathrm{~g}$ was performed on 9 August 2018 to avoid reduction of growth by density limitation (Fig. 4). During this harvest, which fell in the ARS (autumn reproductive season), all fertile thalli (which were the vast majority but not counted at that point) were removed and the $20 \mathrm{~g}$, which were used for the continuation of the culture, consisted only of vegetative thalli. Thus, the ratio of "spring and autumn bloomers" to "only spring bloomers" in the cultivated biomass was probably shifted from its natural value in the field strongly towards "only spring bloomers." This was reflected in the fertility during the continuing ARS 2018 as well as during the ARS 2019, when only few sexual organs were formed (6 November 2018: $16.2 \pm 1.4 \%$; 30 October 2019: $30.8 \pm$
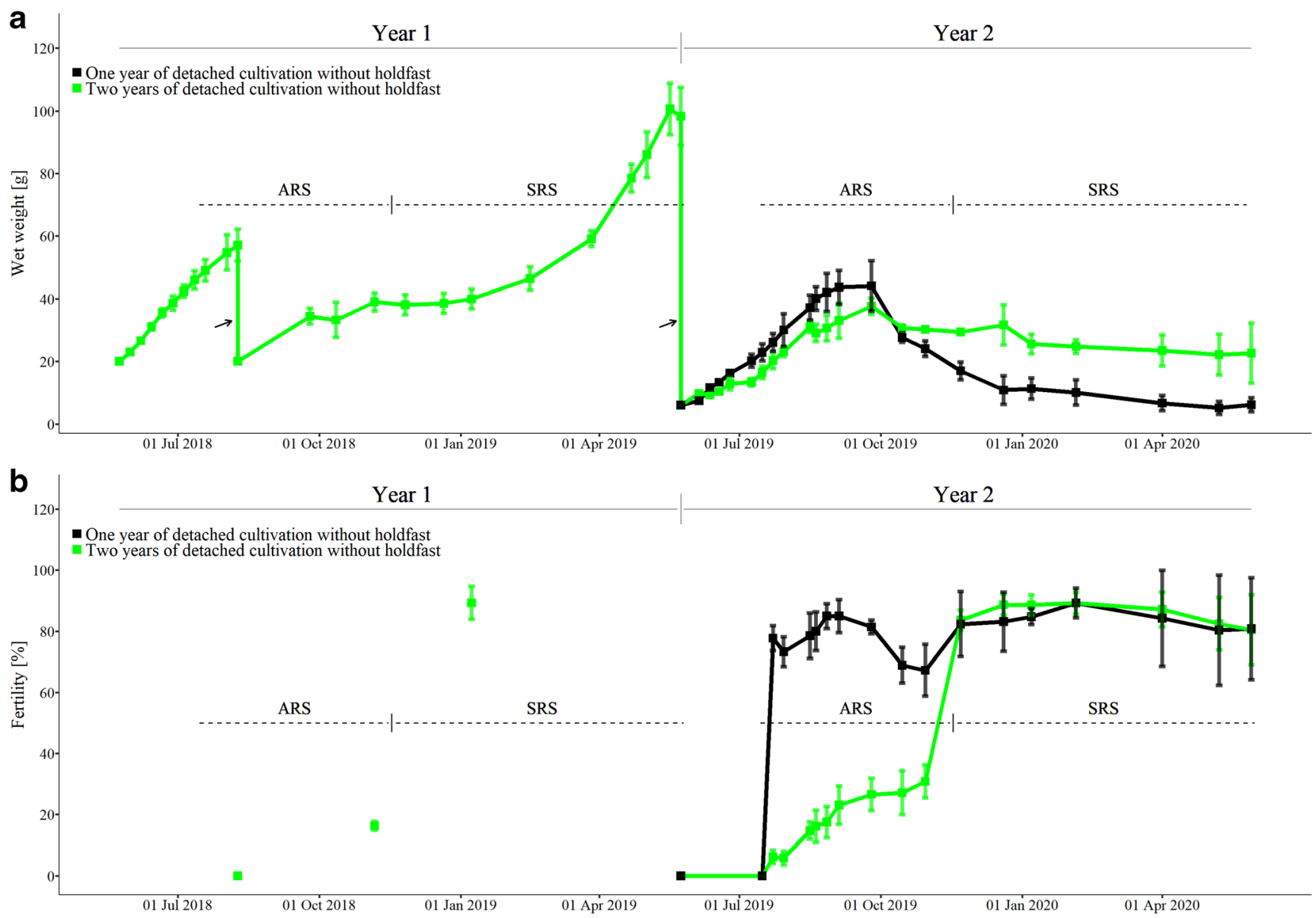

Fig. 4 Unattached cultivation of formerly attached $F$. vesiculosus thalli over 2 years (24 May 2018-29 May 2020). Comparison between first and second year of cultivation of the same thalli (first vs. second year of the light green group) and thalli cultivated unattached for 1 and 2 years at the same time period (black vs. light green group during year 2). a Wet

weight. b Fertility. During year 1, two intermediate harvests have been performed (09 August 2018, 24 May 2019, indicated by arrows). Data displayed as mean $\pm \mathrm{SD}, N=3$ baskets. ARS, autumn reproductive season (July to November); SRS, spring reproductive season (November to May) 


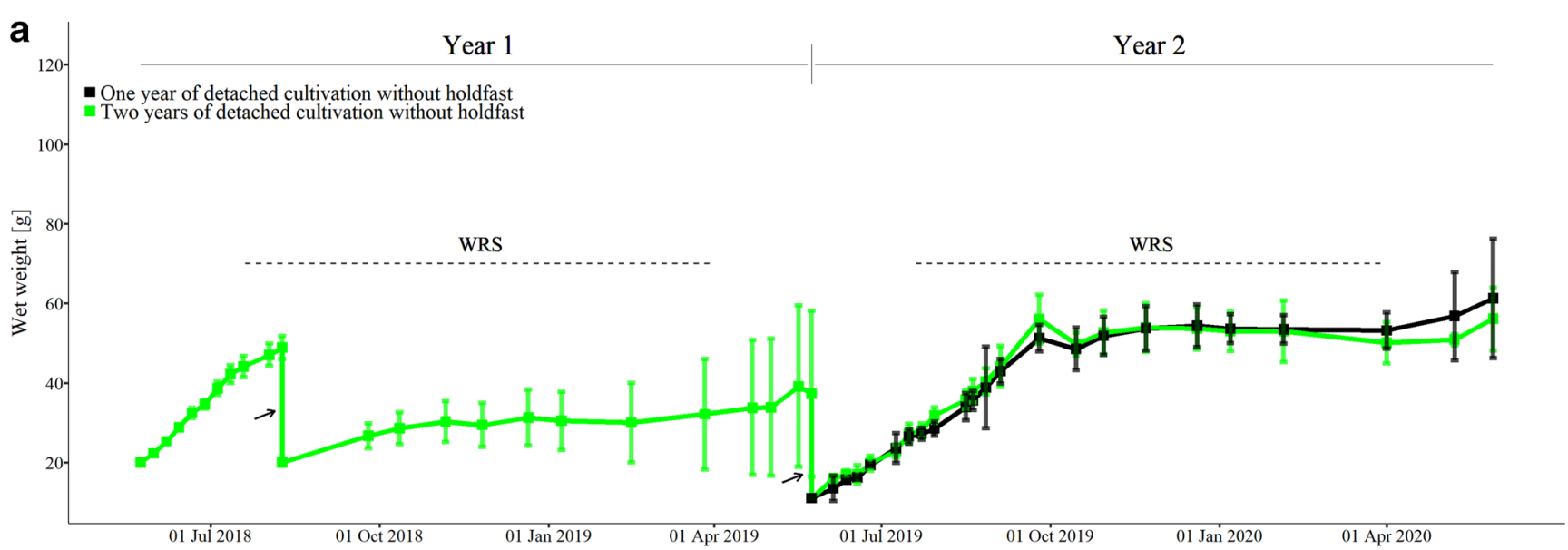

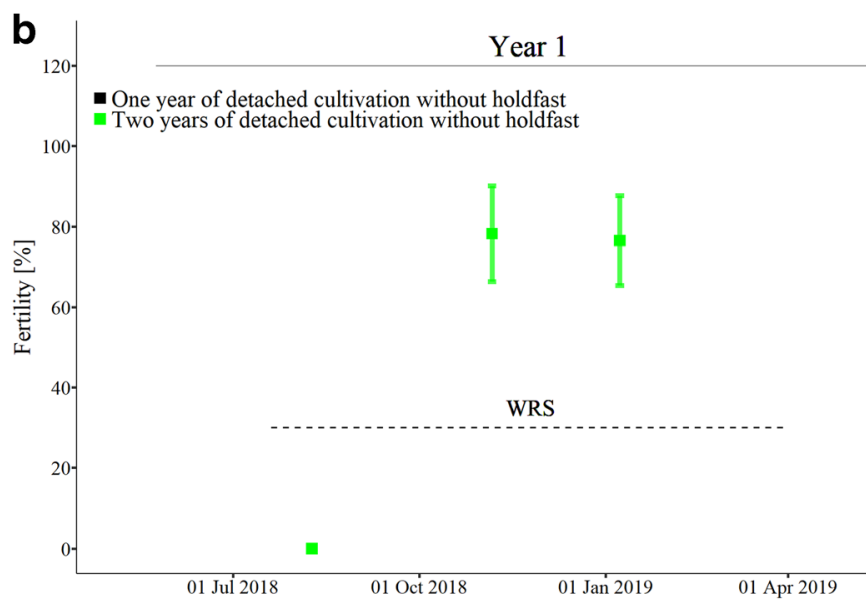

Fig. 5 Unattached cultivation of formerly attached $F$. serratus thalli over 2 years (24 May 2018-29 May 2020). Comparison between first and second year of cultivation of the same thalli (first vs. second year of the light green group) and thalli cultivated unattached for 1 and 2 years at the same time period (black vs. light green group during year 2). a Wet

$5.4 \%$ fertility). The parallel group, which was added in year 2, consisted of the natural mixture between the two genotypes and produced up to $67.2 \pm 8.5 \%$ receptacles during ARS 2019. Thus, the difference in fertility during ARS 2019 has to be considered as artifact caused by the shift of the genotype ratio. This artificial difference led to different growth patterns between the two groups: the thalli in the first cultivation year showed a marked weight decrease after the ARS 2019 due to many degrading receptacles. The thalli in the second cultivation year produced less receptacles during the ARS 2019 and did consequently not show this marked weight decrease (Fig. 4).

A valid comparison of fertility was possible during the SRS 2020, when both genotypes were expected to produce receptacles. During this reproductive season, the fertility of thalli which were in the first year of cultivation (7 January 2020: $84.8 \pm 2.6 \%$ ) was statistically equal to the fertility of thalli which were in the second year of cultivation (7 January 2020: $88.6 \pm 3.4 \%$; Welch's two-sample $t$ test: $p=0.203)$. The group cultivated for 2 years showed statistically equal fertilities during the SRS of both years (8 January 2019: $89.3 \pm 5.4 \%, 7$ January 2020: $88.6 \pm$ 3.4\%; Welch's two-sample $t$ test: $p=0.445$ ).

The frequent measurements during year 2 revealed very rapid increases in fertility for both groups. The actual fertility increase might have been slightly more gradual, but small differences in the timing of the receptacle initiation of individual apices were not detectable by the measurement method.

For $F$. serratus, no difference in fertility was observed between year 1 and year 2 (6 November 2018 vs. 30 October 2019: Welch's two-sample $t$ test: $p=0.138$ ), as well as between thalli cultured for 1 and 2 years during year 2 (30 October 2019: Welch's two-sample $t$ test: $p=0.234$, Fig. 5). The typical reproductive season in winter was clearly observable. Although the same harvests as for $F$. vesiculosus were performed during year 1 , no artificial change in reproductive behavior could be observed, because $F$. serratus only occurs with one known genotype with respect to the reproductive season. The weight loss due to the degradation of receptacles 

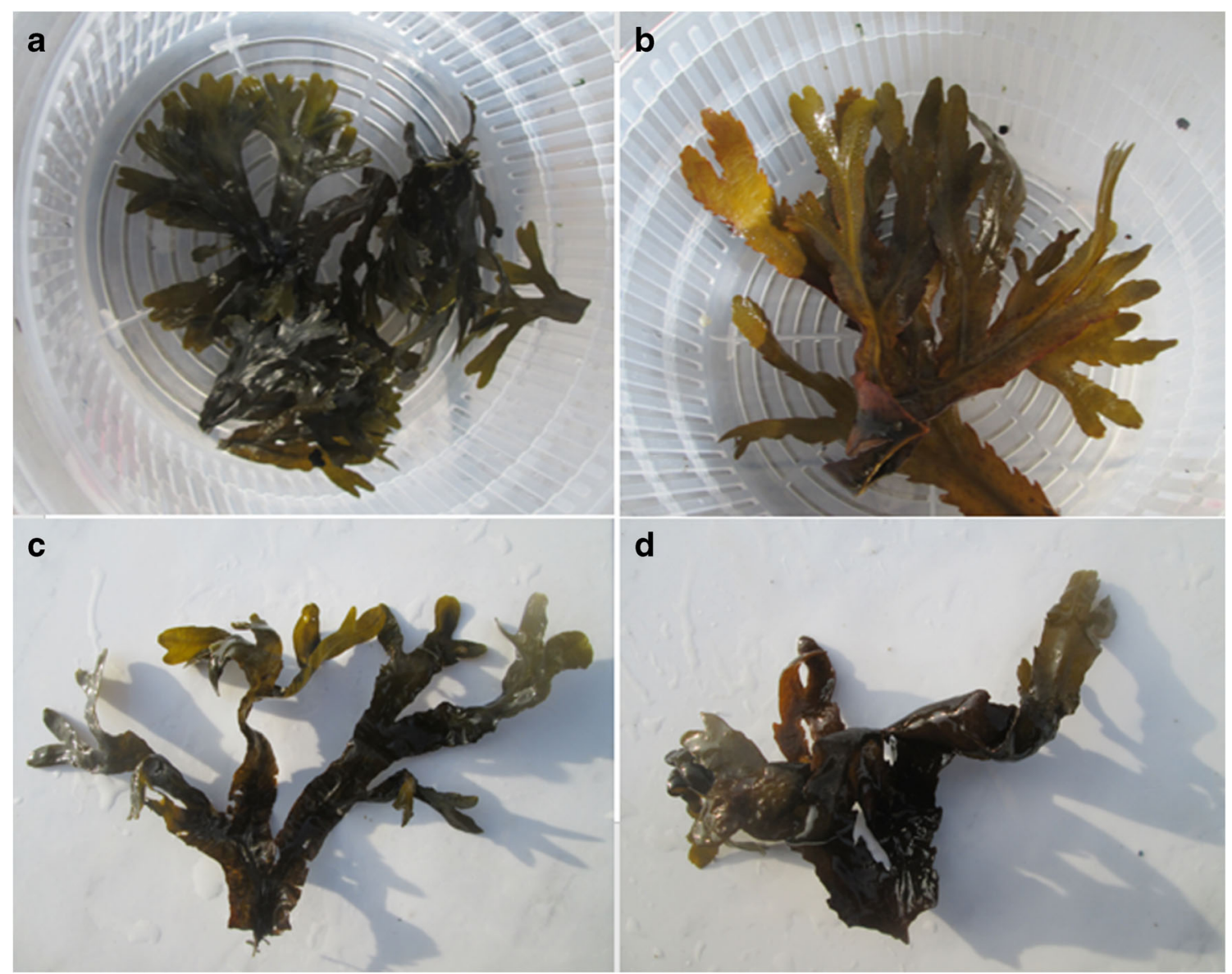

Fig. 6 a, b $F$. vesiculosus and $F$. serratus thalli from the attached origin after collection from the field with typical flat and well-oriented shape. c,

d $F$. vesiculosus and $F$. serratus thalli showing disoriented, twisted shape after ca. 14 months of unattached culture

was partly compensated by new biomass from vegetative apices, which was well visible at the end of year 1 and year 2 .

\section{Fertility of unattached Glücksburg population in culture (experiment 3)}

Thalli of the Glücksburg population remained almost entirely infertile during 1 year of cultivation; only very few receptacles were formed during spring 2020 leading to a maximum fertility of $2.0 \pm 3.1 \%$ at 29 June $2020\left(t_{\text {end }}\right)$. Within the first month of cultivation, the weight increased from $58 \pm 3$ to $144 \pm 15 \mathrm{~g}$ (Fig. 7a). However, growth did not continue in the following, probably due to decreasing light and temperature in autumn and commencing grazing. Beginning in autumn 2019 and especially during spring 2020 , the number of apices was strongly reduced by intense grazing by amphipods (Gammarus sp.) and isopods (Idotea baltica), which accumulated in the baskets during the experiment (Fig. 7b). As the grazers in most cases consumed only the fresh apical parts including the meristems, this process did not lead to drastic losses of weight but rather limited further growth. The cultures also suffered from coverage by filamentous diatoms during spring 2020, which might have led to an additional reduction of growth during this time of the experiment. Intact apices continued to produce fresh tissue during the entire experiment, visible by the light green color of newly formed apical tissue. Therefore, a suppressing effect of the general culture conditions (basket, location) on the growth of the thalli can be excluded.

\section{Discussion}

In this study, we confirmed the expectation that the typical fertility of attached Fucus populations (F. vesiculosus: $80 \%$ receptacles, $F$. serratus: $\sim 70 \%$ receptacles) is detrimental for unattached vegetative cultivation. As expected from wild populations, degrading receptacles caused significant biomass losses in experimental cultures with natural fertility, leading to only little overall biomass gain ( $F$. vesiculosus) or even biomass loss (F. serratus, Fig. 3.). The observed growth reduction during reproductive phases was more severe than reported for wild Fucus plants (e.g., Arrontes 1993; Berger 

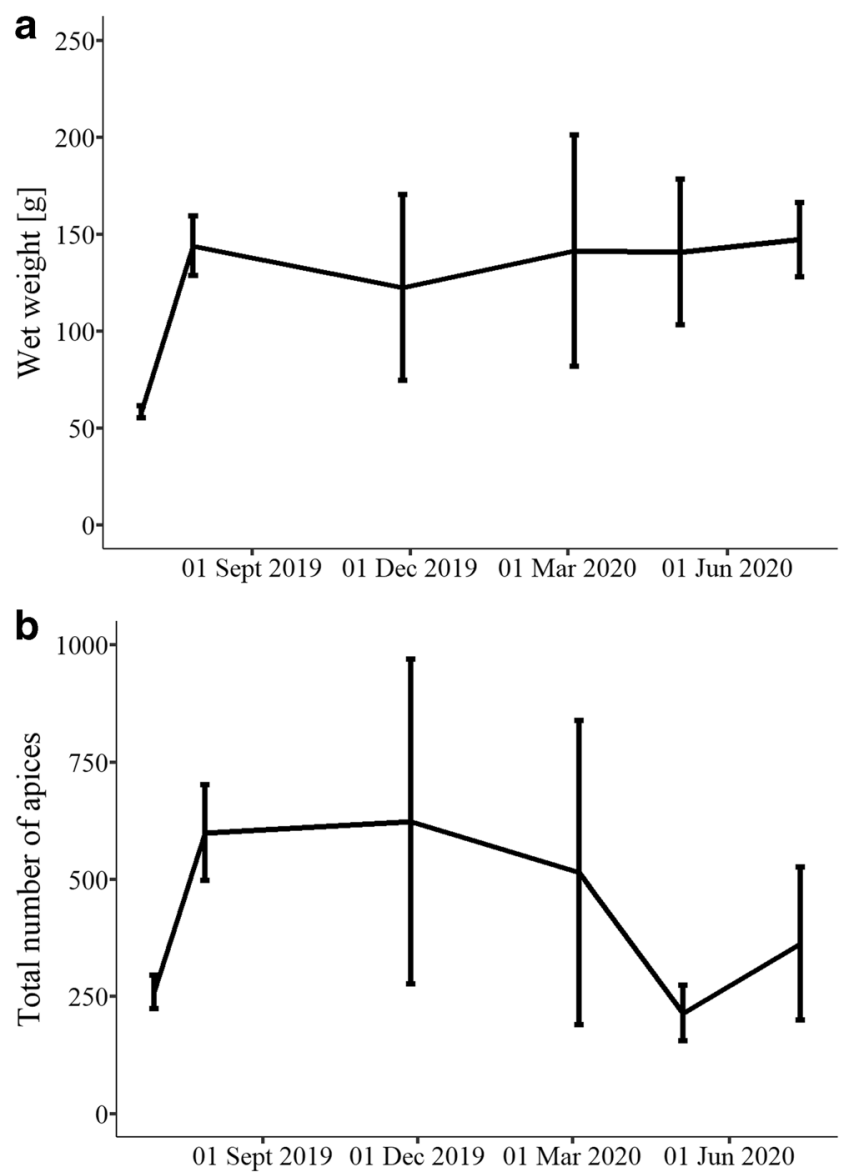

Fig. 7 Cultivation of thalli from unattached Glücksburg population over the course of 1 year. a Wet weight. b Total number of apices. Data displayed as mean $\pm \mathrm{SD}, N=4$ baskets. Heavy grazing is visible by a reduction of the total number of apices in spring 2020

et al. 2001). This was probably due to the fact that fronds were used in the experimental cultures, which sometimes degraded completely, while entire Fucus plants are able to retain the stipe from which growth can continue (Knight and Parke 1950). Our experiment underlined the necessity of lowfertility biomass for successful vegetative unattached Fucus aquaculture.

In experiment 2 , we tested if low-fertility biomass can be obtained from attached thalli through long-term acclimatization in unattached culture. Within a 2 -year period, no acclimatization of formerly attached thalli towards reduced fertility was observed (Figs. 4 and 5). Therefore, we conclude that it is impossible to acclimate attached Fucus populations to low fertility by unattached culture, which is in contradiction to the hypothesis of Maczassek (2014). Maczassek had assumed that the unattached Glücksburg population resulted from the detachment-induced acclimatization of $F$. vesiculosus thalli towards low fertility. Whether other factors present at the growth location of the population (e.g., reduced salinity, low/ high nutrients, low oxygen levels, or others) and not detachment alone are causal for a potential acclimatization is unclear. If so, acclimatization in aquaculture would be complicated, because usually the conditions of the used water body can hardly be changed in the large-scale culture. If the acclimatization process just requires more than 2 years, seedling production would be very ineffective. However, this is unlikely, because no signs for the initiation of an acclimatization process were visible. Other features typical for unattached populations (unoriented growth, reduced size) were induced by unattached culture (Fig. 6). This suggests that these features can be acquired via acclimatization and probably result from the absence of a fixation to the substrate and the concomitant constant orientation in space (Norton and Mathieson 1983).

In experiment 3, we tested if biomass collected from the unattached Glücksburg population retains its low fertility under culture conditions. During 1 year of cultivation, it remained almost entirely receptacle-free (Fig. 7) showing only the minor fertility which is typical for the wild population (pers. observation, Maczassek 2014). Consequently, biomass losses due to receptacle degradation are expected to be very low and generated seedlings have a high probability to contain and retain viable meristems and produce new biomass. Thus, the Glücksburg population seems to be a good candidate for vegetative culture and reproduction of Fucus. Based on the morphology of the Glücksburg population, the produced biomass could be considered as vesiculosus-type biomass.

However, based on our data, it cannot be guaranteed that the fertility of biomass from the Glücksburg population remains low for several years, since a slow backacclimatization towards higher fertilities cannot be excluded. Maczassek (2014) found a maximum of $30 \%$ fertility for the Glücksburg population in mesocosm experiments, which suggests that higher fertilities are possible. So far, all observed fertilities were not high enough to be detrimental for aquacultural success. A genetic determination of the low fertility of the Glücksburg population would be desirable for the planning of future aquaculture efforts. However, it is impossible to prove a genetic fixation at the current state of knowledge, because the genes responsible for receptacle formation are not known and no Fucus genome has been published yet. Even if hybridization or polyploidy would be shown for the Glücksburg population, as have been for other unattached populations by analysis of microsatellites, mtDNA RFLP, and nuclear DNA content (Coyer et al. 2006; Mathieson et al. 2006; Sjøtun et al. 2017), no permanence of low fertility could be guaranteed, because no causal connection between polyploidy/hybridization and low fertility has been shown for Fucus species so far. Therefore, further cultivation trials over longer time spans are necessary to ensure the long-term usability of the Glücksburg population. Based on the results presented here, we assume that biomass from the Glücksburg population retains a low fertility also for longer cultivation periods. 
As the focus of this study was on fertility, no optimization of growth was aimed at in the experimental culture of biomass from the Glücksburg population. Grazing by Gammarus sp. and I. balthica was therefore not sufficiently dealt with, which led to only little growth in the second half of the experimental culture year. If this factor had been controlled, continuous growth could have been expected. Grazing on the thalli from the Glücksburg population seemed to be more intense than grazing on thalli from the attached origin. One explanation is that grazers prefer vegetative material and avoid slimy receptacles (Hemmi et al. 2005). Another explanation is that the Glücksburg population has a comparatively poor grazing defense, which is not known so far, but could be tested in grazer preference experiments (Goecker and Kåll 2003). A reduction of grazing might be possible by regular air exposure or fresh water treatment of the cultivated biomass. Air exposure can in addition be used to reduce the number of fouling organisms (Meichssner et al. 2020). For commercial-scale culture, we suggest baskets of about $1 \mathrm{~m}^{2}$ area, similar to baskets for Eucheuma cultivation shown in Hurtado et al. (2008). This size would allow for easy handling and air exposures could potentially be performed. Plastic or other solid material should be used for the base of the baskets to create a plane area where the biomass can be well spread. If too flexible material is used, the biomass tends to aggregate at the lowest point, which limits growth (own observation). An alternative option would be cultivation in land-based tanks similar to Gracilaria tank cultures (Friedlander and Levy 1995). In this case, grazing could be excluded by pre-filtering the used seawater.

The principle of using unattached Fucus populations for vegetative aquaculture can of course be applied at other locations, too. Unattached populations with low fertility are known from other parts of the Baltic Sea as well as from many coasts of the North Atlantic and the North Pacific (Luther 1981; Norton and Mathieson 1983; Neiva et al. 2012). Some populations are genetically affiliated to $F$. serratus, $F$. gardneri, F. ceranoides, and $F$. spiralis; thus, biomass other than the vesiculosus type can potentially be produced (Norton and Mathieson 1983; Neiva et al. 2012). However, the principle might also be used for the culture of other genera of the Fucales, as unattached populations with low fertility are also known from Ascophyllum, Hormosira, and Sargassum (Norton and Mathieson 1983).

A main concern with the commercial utilization of unattached populations is that they are not very large in most cases and therefore prone to extinction, not only by environmental change but also by random events. Unattached populations from the Baltic Sea, like the one from Glücksburg, are therefore listed by HELCOM as endangered habitats (HELCOM 2013). The continued existence of these populations should therefore always be prioritized before commercial utilization. In our opinion, a use of unattached populations as seedling source could be approved by governmental authorities, if the following conditions are fulfilled: (1) a maximum of $5-10 \%$ of the standing stock is collected and (2) the collection of material is accompanied by regular monitoring of the population, which guarantees the maintenance of the population size. We suggest that only little amounts are collected as stock, from which larger amounts are produced to start commercial culture. Optimally, seedling biomass has to be taken only once and can be generated from culture in subsequent growing seasons.

\section{Conclusion and outlook}

Low fertility has proven to be crucial for unattached vegetative aquaculture of Fucus species. Based on our results, biomass with this feature can only be obtained from unattached populations, like the Glücksburg population in the western Baltic Sea. For successful implementation, the fertility has to remain low over consecutive years in culture, and grazing has to be controlled. Both require further studies. The relatively easy cultivation protocol presented here offers not only a possible solution for the production of Fucus biomass but could also be applied for the cultivation of other species of Fucales for scientific and commercial purposes.

Supplementary Information The online version contains supplementary material available at https://doi.org/10.1007/s10811-021-02419-x.

Acknowledgments Open Access funding enabled and organized by Projekt DEAL. We want to thank Kieler Meeresfarm GmbH \& Co. KG for providing the space for the experiments and a lot of help with construction and maintenance. Special thanks go to Florian Weinberger for the helpful advice on the study concept.

Author contributions Rafael Meichssner designed and conducted the experiments, performed the statistical analysis, and wrote the manuscript. Peter Krost assisted in data analysis and Rüdiger Schulz in the study conceptualization. Peter Krost and Rüdiger Schulz reviewed and edited the manuscript.

Funding The study was funded by Studienstiftung des Deutschen Volkes, Fazit-Stiftung, and the InterReg-Deutschland-Denmark project FucoSan.

\section{Compliance with ethical standards}

Conflict of interest The authors declare that they have no conflict of interest.

\section{References}

Arrontes J (1993) Mechanisms of range expansion in the intertidal brown alga Fucus serratus in northern Spain. Mar Biol 141:1059-1067 
Azevedo CI, Duarte PM, Marinho GS, Neumann F, Sousa-Pinto I (2019) Growth of Saccharina latissima (Laminariales, Phaeophycaea) cultivated offshore under exposed conditions. Phycologia 58:504-515

Bäck S, Collins JC, Russell G (1991) Aspects of the reproductive biology of Fucus vesiculosus from the coast of SW Finland. Ophelia 34:129141

Baker SM, Bohling MH (1916) On the brown seaweeds of the salt marsh II. Their systematics, relationships, morphology and ecology. J Linn Soc Lond Bot 43:325-380

Berger R, Malm T, Kautsky L (2001) Two reproductive strategies in Baltic Fucus vesiculosus (Phaeophyceae). Eur J Phycol 36:265-273

Brenchley JL, Raven JA, Johnston AM (1996) A comparison of reproductive allocation and reproductive effort between semelparous and iteroparous fucoids (Fucales, Phaeophyta). Hydrobiologia 326-327: 185-190

Bundesamt für Naturschutz (2013) Rote Liste gefährdeter Tiere, Pflanzen und Pilze Deutschlands, Band 2: Meeresorganismen. BfNSchriftenvertrieb, Bonn, Bad Godesberg, pp 179-218

Catarino MD, Silva AM, Cardoso SM (2018) Phycochemical constituents and biological activities of Fucus spp. Mar Drugs 16:249

Cherry P, O’Hara C, Magee PJ, McSorley EM, Allsopp PJ (2019) Risks and benefits of consuming edible seaweeds. Nutr Rev 77:307-329

Coyer JA, Hoarau G, Pearson GA, Serrão EA, Stam WT, Olsen JL (2006) Convergent adaptation to a marginal habitat by homoploid hybrids and polyploid ecads in the seaweed genus Fucus. Biol Lett 2:405408

Ferreira RM, Ribeiro AR, Patinha C, Silva AMS, Cardoso SM, Costa R (2019) Water extraction kinetics of bioactive compounds of Fucus vesiculosus. Molecules 24:3408

Friedlander M, Levy I (1995) Cultivation of Gracilaria in outdoor tanks and ponds. J Appl Phycol 7:315-325

Fürhäupter K, Grage A, Wilken H, Meyer T (2008) Kartierung mariner Pflanzenbestände im Flachwasser der Ostseeküste- Schwerpunkt Fucus und Zostera. Schriftenreihe LANU SH- Gewässer, D22

Goecker ME, Kåll SE (2003) Grazing preferences of marine isopods and amphipods on three prominent algal species of the Baltic Sea. J Sea Res 50:309-314

Graham LE, Graham JM, Wilcox LW (2009) Algae, 2nd edn. Pearson Education, San Francisco

Graiff A, Dankwoth M, Wahl M, Karsten U, Bartsch I (2017) Seasonal variation of Fucus vesiculosus fertility under ocean acidification and warming in the western Baltic Sea. Bot Mar 60:239-255

HELCOM (2013) Red list of Baltic Sea underwater biotopes, habitats and biotope complexes. Baltic Sea Environmental Proceedings No. 138

Hemmi A, Mäkinen A, Jormalainen V, Honkanen T (2005) Responses of growth and phlorotannins in Fucus vesiculosus to nutrient enrichment and herbivory. Aquat Ecol 39:201-211

Hurd LH, Harrison PJ, Bischof K, Lobban CS (2014) Seaweed ecology and physiology, 2nd edn. Cambridge University Press, Cambridge

Hurtado AQ, Gerung GS, Yasir S, Critchley AT (2008) Cultivation of tropical red seaweeds in the BIMP-EAGA region. J Appl Phycol 26: $707-718$

Knight M, Parke M (1950) A biological study of Fucus vesiculosus L. and $F$. serratus L. J Mar Biol Assoc UK 29:439-301

Luther H (1981) Occurrence and ecological requirements of Fucus vesiculosus in semi-enclosed inlets in the Archipelago Sea, SW Finland. Ann Bot Fenn 18:187-200
Maczassek K (2014) Environmental drivers of fertility, fertilization and germination of Fucus vesiculosus on the German coast. Dissertation, Christian-Albrechts-University, Kiel

Malm T, Kautsky L, Engkvist R (2001) Reproduction, recruitment and geographical distribution of Fucus serratus L. in the Baltic Sea. Bot Mar 44:101-108

Mathieson AC, Dawes CJ (2001) A muscoides-like Fucus from a Maine salt marsh: its origin, ecology and taxonomic implications. Rhodora 103:172-201

Mathieson AC, Dawes CJ, Wallace AL, Klein AS (2006) Distribution, morphology and genetic affinities of dwarf embedded Fucus populations from the Northwest Atlantic Ocean. Bot Mar 49:283-303

Meichssner R, Stegmann N, Cosin AS, Sachs D, Bressan M, Marx H, Krost P, Schulz R (2020) Control of fouling in the aquaculture of $F$. vesiculosus and $F$. serratus by regular desiccation. J Appl Phycol 32:4145-4158

Moss B (1967) The apical meristem of Fucus. New Phytol 66:67-74

Neiva J, Hansen GI, Pearson GA, Van De Vliet MS, Maggs CA, Serrão EA (2012) Fucus cottonii (Fucales, Phaeophyceae) is not a single genetic entity but a convergent salt-marsh morphotype with multiple independent origins. Eur J Phycol 47:461-468

Netalgae.eu. Accessed 15 July 2018

Nicastro KR, Zardi GI, Teixeira S, Neiva J, Serrao EA, Pearson GA (2013) Shift happens: trailing edge contraction associated with recent warming trends threatens a distinct genetic lineage in the marine macroalga Fucus vesiculosus. BMC Biol 11:1-13

Nienburg W (1925) Eine eigenartige Lebensgemeinschaft zwischen Fucus und Mytilus. Ber Deut Bot Ges 43:292-298

Nienburg W (1931) Fucus mytili spec. nov. Ber Deut Bot Ges 50:28-41

Nienhuis PH (1970) The benthic algal communities of flats and salt marshes in the Grevelingen, a sea arm in the south-western Netherlands. Neth J Sea Res 5:20-49

Norton TA, Mathieson AC (1983) The biology of unattached seaweeds. In: Round FE, Chapmann DJ (eds) Progress in Phycological Research, vol 2. Elsevier, Amsterdam, pp 333-376

R Core Team (2013) R: a language and environment for statistical computing. R Foundation for Statistical Computing, Vienna. http:// www.R-project.org/. Accessed 19 Oct 2019

Sjøtun K, Heesch S, Lluch JR, Martín RM, Gómez Garreta A, Brysting AK, Coyer JA (2017) Unravelling the complexity of salt marsh 'Fucus cottonii' forms (Phaeophyceae, Fucales). Eur J Phycol 52: 360-370

Torres MD, Kraan S, Dominguez H (2020) Sustainable seaweed technologies, cultivation, biotechnology and applications. Elsevier, Amsterdam

Wallace AL, Klein AS, Mathieson AC (2004) Determining the affinities of salt marsh fucoids using microsatellite markers: evidence of hybridization and introgression between two species of Fucus (Phyaeophyta) in a Maine estuary. J Phycol 40:1013-1027

Yarish C, Pereira R (2008) Mass production of marine macroalgae. In: Jørgensen SE, Fath BD (eds) Ecological Engineering. Vol. 3 of Encyclopedia of Ecology. Elsevier, Oxford, pp 2236-2247

Publisher's note Springer Nature remains neutral with regard to jurisdictional claims in published maps and institutional affiliations. 